\title{
SOBRE O DITONGO NASAL DO NÃO-VERBO À LUZ DA MORFOLOGIA DISTRIBUÍDA
}

\section{ON NASAL DIPHTHONG OF NONVERBAL WORDS IN LIGHT OF DISTRIBUTED MORPHOLOGY}

\author{
Cíntia da Costa Alcântara \\ Universidade Federal de Pelotas, Pelotas, RS, Brasil
}

\begin{abstract}
Resumo: Este estudo tem por alvo a constituição dos vocábulos não-verbais do português terminados em -ão, os quais carregariam morfemas de classe formal, ou sufixos temáticos (e.g., /orfaN+o/ órfão, /maN+o/ mão). Vocábulos assim construídos são interpretados, sob o enfoque teórico da Morfologia Distribuída, como integrantes de uma das classes formais da língua. Os dados apresentados são analisados qualitativamente e os resultados apontam para a pertinência do modelo teórico da DM no tratamento do ditongo nasal, contribuindo, assim, para os estudos sobre o tema no âmbito da fonologia do português.

Palavras-chave: Teoria e análise linguística; Fonologia; português.
\end{abstract}

Abstract: This study focuses on the constitution of nonverbal words of Portuguese ended by nasal diphthong - $\tilde{a}$, which seem to have formal class morphemes, or thematic suffix. Words with such structure (cf. /orfaN+o/ orphan; / $\mathrm{maN}+\mathrm{o} /$, hand) are interpreted, in light of Distributed Morphology, as members of the Portuguese form-classes. The presented data are analyzed qualitatively and the results point to the pertinence of Distributed Morphology in the treatment of the constitution of the nasal diphthong, contributing, thus, for the studies on the subject of the Portuguese phonology.

Keywords: Theory and linguistic analysis; Phonology; Portuguese.

\section{Ditongo nasal no PB}

Segundo Camara Jr. (1970), o ditongo nasal deve ser interpretado como o resultado de um ditongo (VC) acrescido de arquifonema nasal $(\mathrm{N})$ tautossilábico (cf. irmão/irmaoN/). Para ele, as sequências -ãe, -ão, -õe e -ui /uiN/ (cf. muito, ruim) decorrem, pois, de -ai, -au, -ôi, -ui seguidas de travamento nasal. Tal seria o motivo de os ditongos nasais não se confundirem com a realização das vogais nasais ditongadas em final de palavra (cf. [be)j)]). Contudo, é debatida na literatura a constituição do ditongo nasal como VCC. Observe-se, a seguir, a interpretação de Bisol (1998) para o fenômeno.

Bisol refere que sua análise tem como pressuposto básico a hipótese de Mattoso Camara para a vogal nasal do português, a qual deve ser entendida como uma sequência na mesma sílaba de vogal oral e consoante nasal (VN), em que $\mathrm{N}$ é um segmento consonântico nasal subespecificado para traços articulatórios. Entretanto, a autora refuta a hipótese de o ditongo nasal ser interpretado como um ditongo oral seguido de arquifonema nasal em final de 
palavra, uma vez que o sistema do português proíbe configurações como $\mathrm{VC}_{1} \mathrm{C}_{2}$, em que $\mathrm{C}_{2}$ tem de ser ocupada unicamente por /S/. É sob o enfoque da Fonologia Lexical (KIPARSKY, 1985) que Bisol (1998) reinterpreta a hipótese de Mattoso Camara (1970) quanto à constituição do ditongo nasal em português - a nasal sem informação de ponto de articulação, uma sequência VN e o elemento terminal do ditongo, uma vogal temática. A nasal desligada permanece flutuante e, durante a derivação, recobre a rima com os seus traços, o que faz com que ambas as vogais sofram nasalização. Assim se dá a formação do ditongo nasal para Bisol, cuja reinterpretação é feita neste artigo sob o arcabouço da DM, a seguir apresentada.

\section{Teoria e análise}

Com respeito às bases teóricas que norteiam este estudo, a Teoria da Morfologia Distribuída, cujos textos basilares são (HALLE; MARANTZ, 1993, 1994) assume ser a gramática constituída de três módulos autônomos, a Sintaxe, a Morfologia e a Fonologia, considerando a Morfologia a interface entre a Sintaxe e a Fonologia. A autonomia dos referidos módulos significa que cada um deles tem seus próprios princípios e propriedades. Nesses três componentes da gramática, a estrutura das sentenças e palavras é representada por diagramas arbóreos, cujos nós terminais são complexos de traços, tanto fonológicos como não-fonológicos - os morfemas.

O módulo da Sintaxe ocupa-se exclusivamente dos traços nãofonológicos dos morfemas. É um componente gerador de estruturas pela combinação, sob nós terminais, de feixes de traços sintáticos e semânticos, selecionados pelas línguas particulares a partir de um inventário disponibilizado pela Gramática Universal (GU).

O módulo da Morfologia, o qual se atém aos feixes de traços nãofonológicos, bem como aos fonológicos, compreende três etapas - (i) as operações morfológicas, dentre as quais interessa particularmente ao presente trabalho a adição de morfemas, cuja formalização é de uma condição de língua particular ativa não só para o português, mas também para outras línguas românicas, responsável pela inserção de uma posição temática à borda direita da palavra; (ii) a inserção vocabular; e (iii) as regras de reajustamento. Somente após a atuação de operações estruturais, do tipo "insira uma posição temática à borda direita do vocábulo morfológico", conforme (i) (HARRIS, 1996, 1999, para o espanhol; OLTRA-MASSUET, 1999, para o catalão; PEPERKAMP, 1997, para o italiano, entre outros), é chamada a inserção vocabular, cuja responsabilidade é atribuir traços fonológicos - os denominados itens vocabulares (expressões fonológicas) aos nós terminais. Note-se que o conteúdo fonológico de um item vocabular pode ser qualquer sequência fonológica, incluindo zero ou "nulo" (e.g., zero 
$\leftrightarrow[\ldots, V]$, em que ' $\leftrightarrow$ ' representa inserção vocabular). Da mesma forma, o conteúdo de traços, ou conteúdo de inserção, pode ser destituído de informação, em tais casos um item vocabular é elsewhere ou default (e.g., o morfema de classe formal da classe I em português, /o/ $\leftrightarrow$ elsewhere ou default $t$. Por fim, as regras de reajustamento atuam sobre itens vocabulares específicos em um contexto morfológico específico (HARRIS, 1999), o que pode ser observado, em português, na vocalização da soante $/ 1 /$ da raiz $(/ 1 / \rightarrow$ [j]) no contexto do plural (cf. "anel" $\rightarrow$ "ané[j]s").

No módulo da Fonologia, as operações fonológicas manipulam dados advindos da Morfologia, o que explica serem muitas delas sensíveis a informações morfológicas, como se verá mais adiante. Em outras palavras, o módulo da Fonologia lida, particularmente, com os traços fonológicos dos morfemas; não obstante, os traços não-fonológicos também aí têm um papel, embora secundário.

Sob o enfoque da DM, os vocábulos não-verbais do português terminados em ditongo nasal -ão, a exemplo de irmão (/irmaN+o/) e mão $(/ \mathrm{maN}+\mathrm{o} /)$, são interpretados como membros de uma das cinco classes formais da língua e cada um deles carrega um morfema de classe formal (VT) à borda direita do vocábulo morfológico (ALCÂNTARA, 2003). Especificamente em relação ao ditongo nasal, assume-se a visão de Bisol (1998), a qual é reinterpretada pela DM.

Salienta-se que os morfemas de classe formal são traços morfológicos abstratos, sem quaisquer ligações com a Sintaxe, o módulo precedente, tampouco a Fonologia, o seguinte. Todavia, constituem as assinaturas fonológicas de cada uma das classes formais arbitrárias, haja vista que serão interpretados na Fonologia como /o/, /a/, /e/ - as tradicionais classes temáticas - ou mesmo a ausência de informação fonológica, no que respeita às classes atemáticas da língua.

A Classe I, identificada pelo morfema de classe formal /o/ (cf. fogo, tribo, irmão $(/ \mathrm{irmaN}+\mathrm{o} /)$, mão $(/ \mathrm{maN}+\mathrm{o} /)$ ), é uma das maiores e mais produtivas do português. Carrega predominantemente vocábulos masculinos, não obstante aí também se encontrem formas femininas. Nessa classe, assim como na classe II, estabelece-se uma correlação mais estreita entre gênero e classe formal. A classe II abriga todas as palavras terminadas na vogal /a/ (fada, sistema, irmã (/irmaN+a/)); é considerada a classe não-marcada para os vocábulos femininos, mas inclui também inúmeros vocábulos masculinos. A classe III reúne não somente palavras que recebem a vogal epentética /e/ (boate, surfe), mas também aquelas que terminam em consoantes licenciadas para a posição de coda (flor, paz). A classe IV reúne todas as palavras que, a despeito de carregarem uma consoante licenciada para a posição de coda, ainda assim recebem a vogal /e/ (árvore, pele, classe). A classe V identifica-se por agrupar palavras terminadas em vogal, líquida lateral e nasal subespecificada, 
enfim, as tradicionais formas atemáticas (jabuti, farol, jasmim). Ressalta-se que, sob o enfoque teórico aqui assumido, gênero e classe formal são informações idiossincráticas dos radicais não-verbais ${ }^{1}$. A especificação de gênero precede a atribuição de classe formal, cuja apresentação se dá como um traço diacrítico abstrato, o qual é mapeado sobre o morfema de classe formal (VT), que deve se apresentar à borda direita da palavra — condição vigente para o português e para muitas línguas românicas —, a fim de que as palavras sejam morfologicamente bem-formadas, como se verá adiante neste texto.

Considerando-se que o interesse do presente trabalho é analisar a constituição dos vocábulos não-derivados do português terminados em ditongo nasal -ão como portadores da classe I, cujo morfema de classe formal ${ }^{2}$, em termos de traços abstratos, é [T, o qual fonologicamente é interpretado como /o/, apresentam-se lado a lado, na Figura 01, membros da classe I com ambas as terminações oral e nasal. Após, explicações detalhadas são fornecidas referentemente às regras fonológicas de que resultam os vocábulos ilustrados, que carregam terminação nasal.

a. entradas vocabulares dos radicais

/ trib/, f, I

$/ \mathrm{maN} /, \mathrm{f}, \mathrm{I}$

/lob/

/irmaN/

b. derivacôes

tribo

mão

lobo

$[/ \mathrm{trib} /] \mathrm{T} \quad[/ \mathrm{maN} /] \mathrm{T}[/ \mathrm{lob} /] \mathrm{T} \quad[/ \mathrm{graN} /] \mathrm{T}$
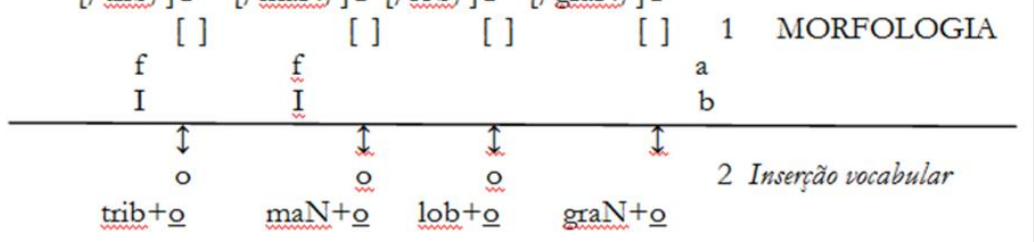

Figura 01 - Ilustrações de membros da classe I

Fonte: Acervo particular do autor

Constata-se, em (a), a dessemelhança com respeito a informações (ou falta delas) nas entradas vocabulares dos radicas de tribo e mão, de um lado, e

\footnotetext{
${ }^{1}$ No presente caso, referimo-nos especificamente aos radicais nominais.

${ }^{2}$ A expressão morfema de classe formal é empregada não só para referir os traços morfológicos abstratos [I], [II], e assim por diante, mas também o traço fonológico correspondente, ou seja, $/ \mathrm{o} /, \mathrm{a} /$, entre outros.
} 
lobo e grão, de outro. Em (b), apresentam-se as derivações ${ }^{3}$ das quatro formas, femininas e masculinas. Na linha 1a, das derivações, enquanto a especificação de gênero feminino (f) está marcada nas entradas vocabulares dos radicais trib-e maN-, não há qualquer marca para os radicais masculinos, lob- e graN-. Isso acontece em virtude de o gênero masculino ser considerado não-marcado para a Classe I, não necessitando, pois, aparecer nas entradas vocabulares, diferentemente do gênero feminino, o qual, por ser considerado marcado no português, deve estar presente nas entradas vocabulares de todas as palavras femininas, independentemente da classe formal. $\mathrm{Na}$ linha $1 \mathrm{~b}$, enquanto os radicais lob- e graN- não apresentam traço de classe formal, em razão de essa classe ser considerada o caso default por excelência, os radicais trib- e maN- apresentam-se com a informação de classe formal, ou seja, o traço diacrítico abstrato de classe formal [ $\mathrm{T}$. Tal mecanismo obsta a incorreta atribuição de tribo e mão à classe formal II, o caso não-marcado para os nomes femininos, evitando assim que emerjam as formas incorretas *triba e *mã. Finalmente, na linha 2, ocorre a operação morfológica de inserção vocabular, a qual é responsável pelo aparecimento da vogal /o/ nos quatro casos, trib $+\mathbf{o}, \mathrm{maN}+\mathbf{o}, \mathrm{lob}+\mathbf{o}$ e graN $+\mathbf{o}$. Somente após essas operações atuarem, no componente morfológico, é que o material fonológico inserido poderá ser manipulado por regras fonológicas, no módulo seguinte. Neste componente, ocorrem, então, as regras fonológicas responsáveis pelas formas de output de todas as palavras, e aqui particularmente aquelas terminadas em ditongo nasal.

Aponta-se para uma diferença fundamental no que respeita à derivação dessas palavras, daquelas desenvolvidas por palavras terminadas em vogais orais. Na Figura 02, apresenta-se o mecanismo que dá conta da derivação dos ditongos nasais. Essa proposta inspira-se na hipótese de Bisol (1998), com relação ao tratamento dos ditongos e vogais nasais do português, segundo a qual o ditongo nasal tem por base $\mathrm{VN}$, em que $\mathrm{N}$ se torna flutuante por desassociação.

\footnotetext{
${ }^{3}$ A numeração conjugada com letras que aparece nas ilustrações na Figura 01, (b), do tipo 1a-b, 2, 3 nada mais é do que um expediente encontrado a fim facilitar a descrição dos mecanismos envolvidos nas derivações.
} 


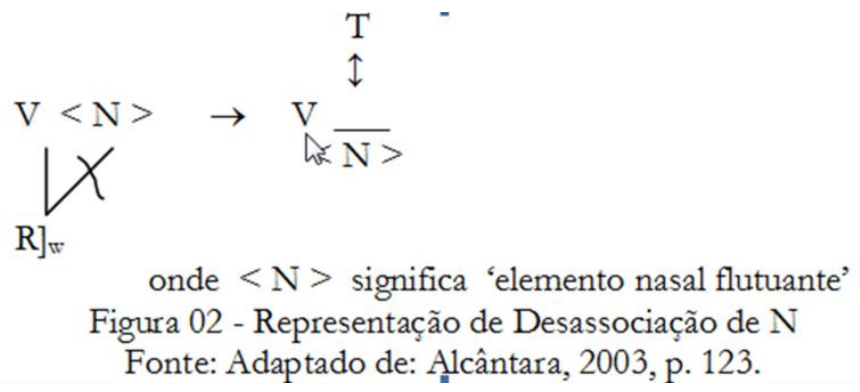

Nesse mecanismo, o elemento nasal que está na posição de coda, à borda da palavra,"]w", é desassociado de seu slot por não possuir traços articulatórios, deixando esta posição disponível no constituinte " $R$ " para a manifestação do morfema de classe formal, "T". A nasal, porém, não é apagada, permanece flutuante, $\langle\mathrm{N}\rangle$, uma vez que, em etapa posterior é reassociada à rima, o que pode ser visto na Figura 03, a seguir.



Figura 03 - Representação da Reassociação de N à Rima Fonte: Adaptado de Alcântara, 2003, p. 123.

A posição deixada vazia por "N" recebe o mapeamento fonológico do traço de classe formal $(\mathrm{T}<->\mathrm{V})$ que representa a classe $[\mathrm{T}$. A nasal, "N", por sua vez percola, reassociada à rima, envolvendo todos os elementos desse constituinte.

Enfim, reinterpretando Bisol por DM, a adjunção do sufixo temático é um processo morfológico, isto é, ocorre no módulo da Morfologia - póssintaticamente, enquanto todos os demais são processos fonológicos, que operam no componente fonológico da gramática, sem descuidar, contudo, da informação morfológica de classe formal que já se faz presente desde o componente precedente, como se pode verificar na Figura 04. 


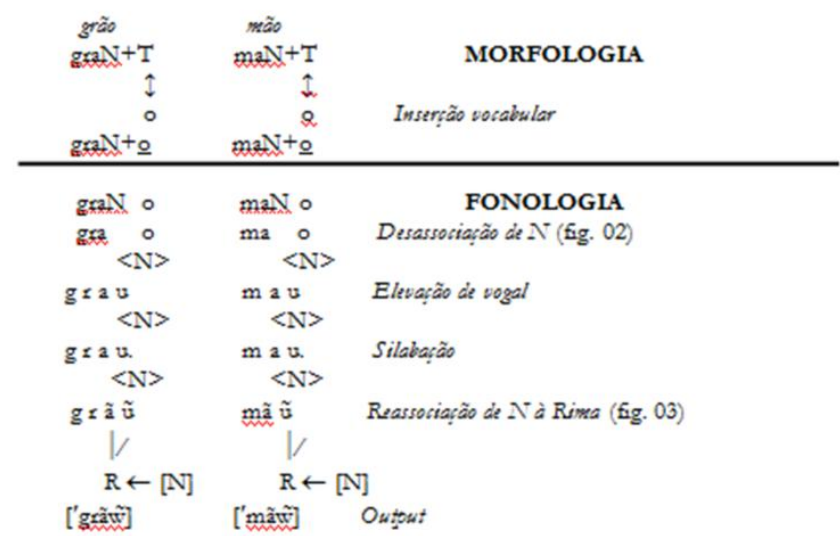

Figura 04 - Representaçĩo completa da derivação de membros da classe I com ditongo nasal Fonte: Acervo particular do autor

Acima da linha horizontal, na Morfologia, verifica-se o processo de inserção vocabular de /o/, como realização do morfema de classe formal, conforme já referido. $\mathrm{Na}$ Fonologia, abaixo da linha horizontal, ocorrem os processos e restrições responsáveis pela manipulação do conteúdo fonológico inserido nas posições terminais (morfemas) da etapa precedente, a Morfologia. O primeiro mecanismo a operar é a desassociação de nasal, Figura 02, pela qual a nasal em coda é desassociada da posição; contudo, o feixe de traços do segmento nasal permanece flutuante " $<\mathrm{N}>$ " e, desta feita, a posição antes por ele ocupada fica disponível para a manifestação do morfema de classe formal. Segue-se a elevação da vogal, regra de aplicação geral na sequência de duas vogais, e após a silabação, da qual resultam sílabas bem formadas. Posteriormente, aplica-se a operação de reassociação de "N" à Rima, Figura 03, que gera o ditongo nasal. Como resultado da aplicação de todos esses processos resulta as formas de output corretas: grãw, mãw ${ }^{4}$.

Outrossim, conforme referido neste texto, formas como *questã, *indigestã, *congestã são comuns em dialetos populares. Sob a presente proposta, o que se observa é uma troca sistemática de /o/ por /a/, ou seja, de classe I para classe II. Se os traços [I], [II] e os demais não são meros rótulos que identificam os membros de classe formal, devem então desempenhar outro papel nas generalizações linguísticas. Eis o que os referidos dados parecem comprovar. Pelo fato de formas femininas terminadas em /o/ serem

\footnotetext{
${ }^{4} \mathrm{O}$ presente estudo não focaliza a questão 'gênero' relativamente às classes formais. Maiores informações sobre a correlação existente entre classe formal e gênero gramatical pode ser encontrada em Alcântara (2003).
} 
interpretadas como marcadas, uma vez que a forma não-marcada para o feminino é a terminação /a/, o feixe de traços que caracteriza questão, indigestão, congestão, ou seja, [I, f], é sistematicamente simplificado, fazendo assim com que tais formas passem da classe I para a classe II, as duas únicas classes do português em que há uma estreita correlação entre gênero e classe formal. A referida simplificação ocorre a partir do desligamento do traço marcado, [], e o traço restante na configuração, [f], desencadeia, por sua vez, a regra de redundância morfológica, por meio da qual é atribuído o traço [II] aos radicais femininos, emergindo assim as formas *congestã, *indigestã, *questã. Esse é o tipo de operação que se observa em expressões informais, a saber, servente/serventa, chefe/chefa, parente/parenta, cliente/clienta, e também em formas do português standard, como mestre/mestra, monge/monja, infante/infanta. A diferença estaria somente na constituição do feixe de traços marcados que identifica as formas femininas, aqui constituído como [III, f].

Acredita-se assim que os dados analisados fornecem evidências de que a identificação de radicais acabados em -aN, sob as classes I e II, como receptores de /a/ e /o/, respectivamente, está correta. São, pois, legítimas manifestações fonológicas dos morfemas de classe formal [I] e [II]. Além disso, esses dados trazem suporte à postulação da existência dos traços de classe formal como legítimos traços na acepção standard, não só atuantes na catalogação de membros de classe formal, bem como participantes de outras regras da gramática, como, por exemplo, aquelas que simplificam feixes de traços morfológicos, levando assim a que membros de uma dada classe migrem para outra de marcação menor. Passa-se às considerações finais.

\section{Considerações finais}

À guisa de conclusão, sob o modelo teórico da Morfologia Distribuída, para que um vocábulo não-verbal alcance o status de bem-formado morfologicamente, indispensável é a presença do nó terminal morfológico "T" na representação morfossintática da palavra. É no componente morfológico da gramática que ocorrem os mecanismos responsáveis pela boa formação morfológica de nomes e adjetivos do português, independentemente da terminação de que sejam portadores. A ideia que subjaz a essa proposta teórica é a de que a representação morfossintática da palavra independe de sua representação fonológica. Uma vez constituída a estrutura morfológica das palavras, a etapa seguinte, ainda no componente da morfologia, incumbe-se de inserir material fonológico, através da operação de inserção vocabular, aos morfemas temáticos, no presente caso, o morfema de classe formal da classe I, o qual se manifesta como a vogal /o/ tanto para as palavras terminadas nesta vogal, quanto aquelas terminadas no ditongo nasal -ão. Em outras palavras, 
não há níveis distintos para a entrada do morfema de classe formal para palavras terminadas em vogais orais e em ditongo nasal, o que decorre da organização da gramática sob a DM - o que parece apontar para a pertinência deste modelo teórico no tratamento do ditongo nasal -ão como portador do morfema de classe formal /o/.

\section{REFERÊNCIAS}

ALCÂNTARA, C. da C. As Classes Formais do Português e sua Constituição: Um estudo à luz da Teoria da Morfologia Distribuída. Tese (Doutorado em Letras). Pontifícia Universidade Católica do Rio Grande do Sul. Porto Alegre - RS, 2003.

BISOL, L. A nasalidade, um velho tema. D.E.L.T.A. n. 14(especial), p. 27-46, 1998.

CALABRESE, A. Some remarks on the Latin case system and its development in Romance. In: E. Trevino; J. Lema (Eds.). Theoretical Analysis of Romance Languages. Amsterdam: John Benjamins, 1998, p. 71-126.

CAMARA Jr., J. M. Estrutura da Língua Portuguesa. Petrópolis: Vozes, 1970.

HALLE, M.; MARANTZ, A. Some key features of distributed morphology. MITWPL 21: Papers on Phonology and Morphology, p. 275-288, 1994.

. Distributed morphology and pieces of inflection. In: K. Hale; S. J. Keyser (Eds.). The View from the Building 20: Essays in Honor of Sylvain Bromberger. Cambridge, Massachusetts: MIT Press, 1993.

HARRIS, J. W. Nasal depalatalization no, morphological wellformedness si; the structure of Spanish word classes. MITWPL 33: Papers on Syntax and Morphology, p. 47-82, 1999.

. The syntax and morphology of class marker suppression in Spanish.

In: Karen Zagona (Ed.). Grammatical Theory and Romance Languages. Amsterdam: John Benjamins, 1996.

KIPARSKY, P. Some consequences of Lexical Phonology. Phonology Yearbook, p. 285-138, 1985.

OLTRA-MASSUET, I. On the Notion of Theme Vowel: A New Approach to Catalan Verbal Morphology. MIT: SM Thesis, 1999.

PEPERKAMP, S. Prosodic Words. Dissertation (Doctoral), Universiteit van Amsterdam. The Hague: Holland Academic Graphics, 1997. 